\title{
Can we augment web responses with telephonic responses to a graduate destination survey?
}

\author{
Jacques du Toit
}

Department of Town and Regional Planning, University of Pretoria, Private Bag X20, Hatfield, Pretoria, 0028, South Africa

Corresponding author. Email: jacques.dutoit@up.ac.za

Jacques du Toit was previously a Senior Researcher in the Human Resources Development Research Programme at the South African Human Sciences Research Council. Given his background, he was contracted to assist with the design and analysis of the 2010 Western Cape graduate destination survey.

The 2010 Western Cape graduate destination survey utilised a sequential mixedmode design in which an initial web survey was augmented with an equivalent telephonic survey. This article examines mode effect in the Western Cape survey in terms of overall effect size and the bearing it had on the main outcome of the study. Thus, can we augment web responses with telephonic responses to alumni or graduate destination surveys? Standardized residuals and Cramér's $V$ are used to determine mode effect across two scenarios, a full sample versus a subsample, and using two categorical questions with different numbers of response categories. Overall effect size appears to be small in the first question, but increases noticeably together with non-responses in the second question that has many more response categories. Web responses to alumni or graduate destination surveys can perhaps be augmented with telephonic responses if necessary, provided response categories are kept to a minimum and interviewers are trained properly and monitored for possible interviewer misbehaviour. The benefit of obtaining larger samples should then also outweigh the benefit of using web surveys alone.

Keywords: alumni survey; graduate destination survey; web survey; telephonic survey; mixed-mode survey; mode effect

\section{Introduction}

Mixed-mode surveys are often used to extend survey coverage and increase counts of 
responses in an era where response rates seem to be decreasing. Yet, it is widely accepted that differences between survey modes in terms of administration, medium, and control, invariably effect responses. While there are different modes of surveys, this article focuses specifically on how a large-scale sequential mixed-mode survey, in which an initial web survey was augmented by an equivalent telephonic survey, affect responses. There are two reasons for focusing on these two modes; (1) web surveys are nowadays arguably a preferred mode given the mode's time- and cost efficiency (provided target populations are 'online'), and (2) web and telephonic modes are fundamentally different, especially in terms of medium and control, with web being visual (the respondent can see questions together with response formats) where the respondent is largely in control, and telephonic being aural (an interviewer reads questions and response options one-by-one) where the interviewer is largely in control.

Despite decades since the advent of both web and especially telephonic surveys, there is a relatively small number of studies comparing the general effect of different modes on responses, let alone in alumni or graduate surveys, although much can be gained from these few studies (e.g., see Albaum et al. [2004], De Leeuw [2005], Dillman and Christian [2005, 31], and Braunsberger, Wybenga and Gates [2007, 759]). While web surveys used to be regarded as a supplement to telephonic surveys (Albaum et al. 2004) with the 90s being the heyday of CATI (Computer Assisted Telephone Interviewing), telephonic surveys may probably now be regarded as a supplement to web surveys.

Recurring findings regarding how web compares to telephonic mode in terms of effect on responses can be summarized as follows: Web surveys usually result in (1) greater disclosure (i.e., respondents are more likely to report sensitive information) (Taylor 2000, 53; De Leeuw 2005, 236; Kreuter, Presser and Tourangeau 2008, 862- 
863; Stephenson and Crête 2010, 27), (2) less extreme checking / more neutral and negative evaluations on scaled items (which is supposedly a more accurate reflection of respondents' attitudes and perceptions) (Taylor, 2000, 53; Albaum et al. 2004, 359; De Leeuw 2005, 246; Braunsberger, Wybenga and Gates 2007, 759; Dillman et al. 2009, 1; Stephenson and Crête, 2010, 28), and (3) less social desirability bias and less acquiescence (i.e., a tendency amongst web respondents to give fewer favourable responses and to agree less with normative statements compared to telephonic respondents) (De Leeuw 2005, 237 \& 245; Dillman and Christian 2005, 41; Greene, Speizer and Wiitala 2008, 230; Maguire 2009, 3528; Dillman et al. 2009, 3). On the other hand, telephonic surveys usually result in (1) higher response rates (Albaum et al. 2004, 359; Kreuter, Presser and Tourangeau 2008, 864), (2) fewer skipped questions or non-responses (although web surveys can be programmed to force responses) (Albaum et al. 2004, 359; De Leeuw, 2005, 236; Braunsberger, Wybenga and Gates 2007, 759; Greene, Speizer and Wiitala 2008, 230), and (3) fewer 'don't know' / 'unsure' responses (Taylor 2000, 53). Also, web surveys are said to result in more primacy effects (i.e., a tendency to select response categories near the top), while telephonic surveys result in more recency effects (i.e., a tendency to select an option read out closer towards the end) (De Leeuw 2005, 245-246). However, Dillman and Christian $(2005,42)$ conducted several experiments and found inconsistent evidence regarding primacy- and recency effects, which makes the issue of primacy versus recency effects less conclusive than the findings mentioned earlier.

Still, how do these effects on responses even out in mixed-mode surveys? Stated differently, is one mode clearly better than the other, or, can web and telephonic responses be analysed as a single sample without considering mode effect? Stephenson and Crête (2010) regard web surveys to be equally viable compared to telephonic 
surveys, while Braunsberger, Wybenga and Gates (2007) as well as Kreuter, Presser and Tourangeau $(2008,864)$ found that web surveys produce more reliable responses than telephonic ones. Given a lack of studies to confirm the merits of one or the other as a rule, neither web nor telephonic surveys can yet be said to be better or worse than the other, while much depends on how surveys are designed, administered and managed, as well as the subject matter and characteristics of the population being surveyed.

Moreover, the findings above regarding how web compares to telephonic mode in terms of effect on responses pertain mostly to aspects of respondent behaviour in particular contexts (e.g., interviewer presence versus absence) and question formats (e.g., categorical versus scaled questions).

While these findings improved our understanding of how to design, administer and manage surveys to control for mode effect as much as possible, the question still remains what the overall effect of mixed-mode surveys are, i.e., should we regard mode effect as significantly impacting the overall outcome of a study? Mode effect remains an important consideration, since mixed-mode surveys are likely to become more popular as a strategy to increase response rates. Moreover, in the messy world of applied research, modes are often mixed by augmenting one mode with another pending response rates. Stephenson and Crête (2010) found that although web and telephonic responses differed in a survey of political behaviour in Canada, analyses from one set or the other resulted in few inferential differences and that the overall effect resulting from the difference in mode appeared to be minimal. However, more research is needed in different contexts about the effect of mixed-mode, and sequential mixed mode surveys in particular, so that researchers can make more informed decisions whether to use mixed-modes, and, if so, the extent to which results can be analysed as a single sample and inferences be made about a population. 
The purpose of this article is therefore to examine mode effect in terms of overall effect size in a large-scale graduate destination survey in the Western Cape, South Africa, that utilized a sequential mixed-mode design in which an initial web survey was augmented with an equivalent telephonic survey (e.g., see De Leeuw [2005, 240-241]). A graduate destination survey, also known as an 'alumni' or a 'tracer' survey, focuses on the transition from study to work, as well as other graduate attributes such as migration and further study (e.g., see Alderman, Towers and Bannah [2012, 265]). These surveys are becoming increasingly important not only for institutional planning and research purposes, but also for higher education, labour market and social capital studies. Examining mode effect using a graduate destination survey as an example is also particularly relevant as such surveys may often incorporate both web and telephonic mode due to the availability of both email addresses and phone numbers from university records. Apart from Sakshaug, Yan and Tourangeau (2010) who examined mode effect on sensitive questions in an alumni survey, there are few if any studies examining mode effect in terms of overall effect size in alumni or graduate destination surveys.

\section{The 2010 Western Cape graduate destination survey}

The Western Cape graduate destination survey was commissioned in 2012 by the Cape Higher Education Consortium (CHEC) as the first large-scale graduate destination survey in South Africa involving an entire province and all its universities. The CHEC represents all four universities in the province, including the Cape Peninsula University of Technology (CPUT), Stellenbosch University (SU), the University of Cape Town (UCT) and the University of the Western Cape (UWC). The survey aimed to trace the entire cohort of graduates who received any certificate, diploma or degree two years prior to the survey from one of the four universities - a total of 24,710 graduates ( 7441 
at CPUT, 7380 at SU, 6165 at UCT, and 3724 at UWC). The survey, conducted between September and November 2012, about two years after graduates finished their studies, focused mainly on schooling background, experiences of varsity, the transition from study to work, further study, and migration (CHEC 2013).

Although the methodology of the Western Cape graduate destination survey is discussed in detail elsewhere in Assessment \& Evaluation in Higher Education (see Du Toit et al. [2014]), the survey procedures and response rates are briefly outlined below before examining mode effect. After compiling a sample frame using all available contact details from each university's Higher Education Management Information System (HEMIS), as well as updated contact details for students who still held bursaries from the National Student Financial Aid Scheme (NSFAS), almost all of the 24,710 graduates were contactable either by email, phone or post, except 142 graduates or 0.6 $\%$ of the total cohort.

A commercial call centre was appointed to administer the survey initially via web only (see CHEC [2013, 102-111] for a printed version of the questionnaire). Graduates were either emailed, phoned, or posted (in this particular order depending on the availability of contact details), upon which they were introduced to the survey, given informed consent options and guided on how to access the survey online. After exhausting all available contact details, including sending out reminder emails, a total of 2873 valid web-responses was obtained $-11.6 \%$ of the total cohort of 24,710 graduates (6.8\% at CPUT, $11.9 \%$ at SU, $18.1 \%$ at UCT, and $10 \%$ at UWC). Most responses came within the first week after launching the survey, after which responses dropped noticeably despite reminder emails.

Although response rates of around 10\% are normal for web surveys, some stakeholders were nevertheless concerned about the $11.6 \%$ response rate obtained in the 
Western Cape survey and debated the merits of conducting the survey telephonically with non-respondents to increase the response rate. One argument was that a larger sample was desirable for purposes of evidence-based policy, while the counter argument was that a telephonic mode would impact the reliability of responses due to the length of the questionnaire and presence of questions offering numerous response categories. These questions were expected to cause respondent- and interviewer fatigue, or even interviewer misbehaviour, where interviewers skip questions or fabricate responses (e.g., see Braunsberger, Wybenga and Gates [2007, 759-760]).

The policy argument won and the call centre was appointed to conduct telephonic interviews with randomized lists of non-respondents from each university until a total response rate (web and telephonic responses included) of at least $21.5 \%$ was obtained for each university - the maximum rate given time and budgetary constraints. A total of 2687 telephonic responses were eventually obtained, yielding a final total, together with the 2873 online responses, of 5560 responses $-22.5 \%$ of the cohort of 24,710 graduates, with CPUT now at $21.8 \%, \mathrm{SU}$ at $21.6 \%$, UCT at $21.9 \%$, and UWC at $26.7 \%$ (see also Table 1). Eventually, both web and telephonic responses were analysed as a single sample for the final report (see CHEC [2013]).

\section{Examining mode effect}

Mode effect in the 2010 Western Cape graduate destination survey is examined using two categorical questions across two different scenarios. The first question was about 'employment status', which was the most important question in the survey from a policy point of view, considering current debates about unemployment rates amongst graduates in South Africa (e.g., see Van der Berg and Van Broekhuizen [2012]). The question asked all graduates to report their employment status as at the $1^{\text {st }}$ of September 2012 , shortly before the survey was launched on the $12^{\text {th }}$ of September 2012 . The 
question also included various automated filters by which graduates with different employment statuses were filtered to different subsets of questions. Possible mode effect on this particular question would therefore have had a ripple effect throughout much of the remainder of the questionnaire. The second question was about 'job search behaviour', which offered the maximum number of response categories of all questions in the survey - 18 categories in total. This high number of categories made this item the most difficult question to administer telephonically. The question asked all graduates who reported themselves to be employed in the public or private sector (except those who were self-employed in the private sector), to indicate the primary method of finding the job they had on the $1^{\text {st }}$ of September 2012.

Mode effect in both questions is compared across two different scenarios. The first scenario considers the entire sample $(n=5560)$, while the second considers a subsample to reduce the effect of possible group differences between web and telephonic respondents on response variations. Many mode-comparison studies do not appear to control for group differences resulting in a confounding of mode effect with group differences (Vannieuwenhuyze, Loosveldt, and Molenberghs 2010, 1028). A Chisquare Automatic Interaction Detection (CHAID) was used to determine which of a set of graduate descriptors was most associated with survey mode, i.e., the graduate attribute that had the most influence on whether graduates responded online or telephonically. Attributes for which data were available for the entire sample and that were subsequently tested included (1) gender, (2) age, (3) race, (4) graduating university, (5) qualification type, and (6) field of study.

The graduating university had the most influence on whether graduates responded online or telephonically $\left(\chi^{2}(3)=876.985 ; \mathrm{p}=0.000 ; \mathrm{n}=5560\right)$. This contrast was most likely due to variation in record keeping and the quality of contact details 
between the four universities, but also variation in the predominant socio-demographic profile of graduates between universities. The next step was to determine which university would be most suitable as a subsample based on the most equal distribution between web and telephonic respondents. Table 1 shows that Stellenbosch University (SU), a predominantly white Afrikaans-speaking university, came closest to a 50/50 distribution and was therefore selected as the subsample $(\mathrm{n}=1592)$.

Table 1. Distribution of responses by university and survey mode.

\begin{tabular}{|c|c|r|r|r|}
\hline \multirow{2}{*}{ University } & \multirow{2}{*}{ Statistics } & \multicolumn{3}{|c|}{ Survey mode } \\
\cline { 3 - 5 } & & Web & \multicolumn{1}{c|}{ Telephonic } & \multicolumn{1}{c|}{ Total } \\
\hline \multirow{2}{*}{ CPUT } & Count & 509 & 1116 & 1625 \\
\cline { 2 - 5 } & $\%$ & 31.3 & 68.7 & 100.0 \\
\hline \multirow{2}{*}{ SU } & Count & 876 & 716 & 1592 \\
\cline { 2 - 5 } & $\%$ & 55.0 & 45.0 & 100.0 \\
\hline \multirow{2}{*}{ UCT } & Count & 1115 & 233 & 1348 \\
\cline { 2 - 5 } & $\%$ & 82.7 & 17.3 & 100.0 \\
\hline \multirow{2}{*}{ UWC } & Count & 373 & 622 & 995 \\
\cline { 2 - 5 } & $\%$ & 37.5 & 62.5 & 100.0 \\
\hline \multirow{2}{*}{ Total } & Count & $\mathbf{2 8 7 3}$ & $\mathbf{2 6 8 7}$ & $\mathbf{5 5 6 0}$ \\
\cline { 2 - 5 } & $\mathbf{5}$ & $\mathbf{5 1 . 7}$ & $\mathbf{4 8 . 3}$ & $\mathbf{1 0 0 . 0}$ \\
\hline
\end{tabular}

Cross-tabulations of 'employment status' and 'job search behaviour' by survey mode are used to determine mode effect on responses for both the entire sample and the subsample comprising SU. Statistics in Tables $2-5$ therefore include counts, expected counts, column percentages, and standardized residuals for each response category. Standardized residuals of \pm 2 or higher/lower is generally regarded as a conservative indication of statistically significant differences between cells (Agresti 1990, 224). However, considering the sample size of the Western Cape survey and resulting large chi-squares, an even more conservative estimate was adopted by using standardised residuals of \pm 3 or higher/lower as an indication of mode effect on responses in a particular category. 'Non-responses', i.e., the number of respondents that did not report their employment status or method of finding employment (if employed), are noted below column totals. Although non-responses were excluded from the calculation of 
chi-square results, the percentage of non-responses within each survey mode are also shown. Chi-squares are noted beneath each table together with Cramér's $V$ as an indication of overall effect size. Cramér's $V$ was chosen in order to adjust for both the large sample size and the numbers of columns and rows (e.g., see Reinard 2006, 267).

\section{Mode effect in terms of Employment Status}

Table 2 shows graduate employment status by survey mode for the entire sample with highlighted response categories where both standardized residuals equalled \pm 3 or

Table 2. Employment status of graduates by survey mode (all four universities).

\begin{tabular}{|c|c|c|c|c|}
\hline \multirow{2}{*}{$\begin{array}{c}\text { What was your employment } \\
\text { status on the } 1^{\text {st }} \text { of September } \\
2012 ?\end{array}$} & \multirow{2}{*}{ Statistics } & \multicolumn{3}{|c|}{ Survey mode } \\
\hline & & Web & Telephonic & Total \\
\hline \multirow{4}{*}{$\begin{array}{l}\text { Studying fulltime, not working } \\
\text { and not looking for work at all }\end{array}$} & Count & 506 & 346 & 852 \\
\hline & Exp. count & 438.3 & 413.7 & 852.0 \\
\hline & $\%$ & 17.9 & 13.0 & 15.5 \\
\hline & Std. residual & 3.2 & -3.3 & \\
\hline \multirow{4}{*}{$\begin{array}{c}\text { Employed (part- or fulltime) in } \\
\text { the private sector }\end{array}$} & Count & 1171 & 976 & 2147 \\
\hline & Exp. count & 1104.5 & 1042.5 & 2147.0 \\
\hline & $\%$ & 41.4 & 36.6 & 39.0 \\
\hline & Std. residual & 2.0 & -2.1 & \\
\hline \multirow{4}{*}{$\begin{array}{c}\text { Self-employed in the private } \\
\text { sector }\end{array}$} & Count & 82 & 60 & 142 \\
\hline & Exp. count & 73.1 & 68.9 & 142.0 \\
\hline & $\%$ & 2.9 & 2.2 & 2.6 \\
\hline & Std. residual & 1.0 & -1.1 & \\
\hline \multirow{4}{*}{$\begin{array}{c}\text { Employed (part-or fulltime) in } \\
\text { the public sector }\end{array}$} & Count & 788 & 932 & 1720 \\
\hline & Exp. count & 884.9 & 835.1 & 1720.0 \\
\hline & $\%$ & 27.9 & 34.9 & 31.3 \\
\hline & Std. residual & -3.3 & 3.4 & \\
\hline \multirow{4}{*}{ Employed in the informal sector } & Count & 41 & 2 & 43 \\
\hline & Exp. count & 22.1 & 20.9 & 43.0 \\
\hline & $\%$ & 1.4 & .1 & .8 \\
\hline & Std. residual & 4.0 & -4.1 & \\
\hline \multirow{4}{*}{$\begin{array}{l}\text { Unemployed and looking for } \\
\text { work }\end{array}$} & Count & 200 & 307 & 507 \\
\hline & Exp. count & 260.8 & 246.2 & 507.0 \\
\hline & $\%$ & 7.1 & 11.5 & 9.2 \\
\hline & Std. residual & -3.8 & 3.9 & \\
\hline \multirow{4}{*}{$\begin{array}{l}\text { Unemployed, but not looking for } \\
\text { work }\end{array}$} & Count & 41 & 47 & 88 \\
\hline & Exp. count & 45.3 & 42.7 & 88.0 \\
\hline & $\%$ & 1.4 & 1.8 & 1.6 \\
\hline & Std. residual & -.6 & .7 & \\
\hline \multirow{4}{*}{ Total } & Count & 2829 & 2670 & 5499 \\
\hline & Exp. Count & 2829 & 2670 & 5499 \\
\hline & $\%$ & 100.0 & 100.0 & 100.0 \\
\hline & Non-response & $44(1.5 \%)$ & $17(0.6 \%)$ & $61(1.1 \%)$ \\
\hline
\end{tabular}


higher/lower.

Table 2 shows that four of the seven response categories may have been subject to significant mode effects, namely graduates who were 'studying fulltime', 'employed in the public sector', 'employed in the informal sector', and 'unemployed and looking for work'. Yet, to what extent are differences between web and telephonic respondents in these categories due to mode effects as opposed to group differences? For example, a significantly larger percentage of web respondents were studying further compared to telephonic respondents (18\% as opposed to $13 \%$ ). Assuming that many, if not most graduates who were studying further would have been doing so at their alma mater or one of the other three universities in the Western Cape, universities would have been able to provide updated email addresses for many of these graduates and hence would have increased the likelihood of them responding online. In this case, differences between web and telephonic respondents may well be due to group differences more so than mode effect. Secondly, statistically significant larger percentages of telephonic respondents were employed in the public sector or unemployed and looking for work compared to web respondents ( $35 \%$ as opposed to $28 \%$, and $12 \%$ as opposed to $7 \%$ ). Current employment dynamics in South Africa include a government policy of job reservation for previously disadvantaged racial groups, especially in the public sector. Yet at the same time unemployment rates are also higher amongst such groups, especially amongst Black Africans, as was also found in this survey (CHEC 2013, 4142). Further analyses revealed that a statistically significant larger percentage of graduates from previously disadvantaged groups (combined) were in fact telephonic respondents compared to white graduates $(58 \%$ as opposed to $32 \%)\left(\chi^{2}(1)=315.056 ; p\right.$ $=0.000 ; \mathrm{n}=5446$ ) (excluding 114 graduates classified by their universities as either 
'Other' or 'Unknown'), which suggests that differences here between web and telephonic respondents may also be due to group differences more so than mode effect.

On the other hand, a significantly larger percentage of web respondents were employed in the informal sector compared to telephonic respondents (1.4\% as opposed to $0.1 \%$ ), which is surprising given that informal sector employment is still strongly associated with previously disadvantaged groups, while socio-economic conditions that are typically associated with informal sector employment usually result in less access to the web compared to telephone. The 'informal sector' in South Africa comprises unregulated economic activities that are mostly small-scale and survivalist in nature. Here, actual mode effect might be possible, by which web respondents may have felt more free to disclose their employment status as 'informal' compared to telephonic respondents, especially given a negative stereotype that characterizes informal sector employment in South Africa. However, the stereotype explanation is hypothetical, while the actual extent of mode effect in this particular response category remains largely unknown.

In addition, more than double the percentage of web respondents compared to telephonic respondents ( $1.5 \%$ as opposed to $0.6 \%$, or 44 as opposed to 17 respondents) gave no response, which supports findings in the literature that web respondents are more prone towards non-response, even though a $1.5 \%$ refusal rate is arguably quite small for this type of item. Still, despite significant differences in four of the seven response categories, as well as the difference in the proportion of non-responses between web and telephonic mode, a Cramér's $V$ of 0.146 suggests that survey mode had an overall small to medium effect on 'employment status' as far as the entire sample is concerned. (Cohen (1992) provided the following classification of effect sizes as guidelines for the social sciences; coefficients around 0.1 are regarded as 'small', 
coefficients around 0.3 as 'medium', and around 0.5 as 'large'.) Moreover, the overall effect resulting purely from the use of the two different survey modes is probably even smaller than Cramér's $V$ suggests, considering that the inclusion here of the entire sample may have resulted in group differences contributing to the overall effect size. The small effect size here therefore bodes well for the overall outcome of the study, as 'employment' was a major theme in the study. Also, the question on employment status filtered graduates with different employment statuses to different subsets of questions, which means that a significant mode effect here would have had a ripple effect

Table 3. Employment status of graduates by survey mode (SU only).

\begin{tabular}{|c|c|c|c|c|}
\hline \multirow{2}{*}{$\begin{array}{c}\text { What was your employment } \\
\text { status on the } 1^{\text {st }} \text { of September } \\
2012 ?\end{array}$} & \multirow{2}{*}{ Statistics } & \multicolumn{3}{|c|}{ Survey mode } \\
\hline & & Web & Telephonic & Total \\
\hline \multirow{4}{*}{$\begin{array}{l}\text { Studying fulltime, not working } \\
\text { and not looking for work at all }\end{array}$} & Count & 195 & 128 & 323 \\
\hline & Exp. Count & 177.6 & 145.4 & 323.0 \\
\hline & $\%$ & $22.5 \%$ & $18.1 \%$ & $20.5 \%$ \\
\hline & Std. residual & 1.3 & -1.4 & \\
\hline \multirow{4}{*}{$\begin{array}{c}\text { Employed (part- or fulltime) in } \\
\text { the private sector }\end{array}$} & Count & 322 & 242 & 564 \\
\hline & Exp. Count & 310.1 & 253.9 & 564.0 \\
\hline & $\%$ & $37.2 \%$ & $34.1 \%$ & $35.8 \%$ \\
\hline & Std. residual & .7 & -.7 & \\
\hline \multirow{4}{*}{$\begin{array}{c}\text { Self-employed in the private } \\
\text { sector }\end{array}$} & Count & 26 & 24 & 50 \\
\hline & Exp. Count & 27.5 & 22.5 & 50.0 \\
\hline & $\%$ & $3.0 \%$ & $3.4 \%$ & $3.2 \%$ \\
\hline & Std. residual & -.3 & .3 & \\
\hline \multirow{4}{*}{$\begin{array}{c}\text { Employed (part- or fulltime) in } \\
\text { the public sector }\end{array}$} & Count & 266 & 274 & 540 \\
\hline & Exp. Count & 296.9 & 243.1 & 540.0 \\
\hline & $\%$ & $30.7 \%$ & $38.6 \%$ & $34.3 \%$ \\
\hline & Std. residual & -1.8 & 2.0 & \\
\hline \multirow{4}{*}{ Employed in the informal sector } & Count & 7 & 0 & 7 \\
\hline & Exp. Count & 3.8 & 3.2 & 7.0 \\
\hline & $\%$ & $.8 \%$ & $0.0 \%$ & $.4 \%$ \\
\hline & Std. residual & 1.6 & -1.8 & \\
\hline \multirow{4}{*}{$\begin{array}{c}\text { Unemployed and looking for } \\
\text { work }\end{array}$} & Count & 39 & 25 & 64 \\
\hline & Exp. Count & 35.2 & 28.8 & 64.0 \\
\hline & $\%$ & $4.5 \%$ & $3.5 \%$ & $4.1 \%$ \\
\hline & Std. residual & .6 & -.7 & \\
\hline \multirow{4}{*}{$\begin{array}{c}\text { Unemployed, but not looking for } \\
\text { work }\end{array}$} & Count & 11 & 16 & 27 \\
\hline & Exp. Count & 14.8 & 12.2 & 27.0 \\
\hline & $\%$ & $1.3 \%$ & $2.3 \%$ & $1.7 \%$ \\
\hline & Std. residual & -1.0 & 1.1 & \\
\hline \multirow{4}{*}{ Total } & Count & 866 & 709 & 1575 \\
\hline & Exp. Count & 866 & 709 & 1575 \\
\hline & $\%$ & $100.0 \%$ & $100.0 \%$ & $100.0 \%$ \\
\hline & Non-response & $10(1.1 \%)$ & $7(1.0 \%)$ & $17(1.1 \%)$ \\
\hline
\end{tabular}


throughout the remainder of the questionnaire. Table 3 now shows graduate employment status by survey mode for SU only, which partly controls for group differences due to SU's reasonably homogeneous graduate profile in terms of race and socio-economic status compared to some of the other three universities.

In this scenario, none of the response categories yielded significant differences between web and telephonic respondents, i.e., none of the categories have standardized residuals of \pm 3 or higher/lower. Furthermore, the difference in the proportion of nonresponses between web and telephonic respondents is now almost negligible. In fact, the proportion of refusals amongst web respondents is now smaller compared to the entire sample while the proportion of refusals amongst telephonic respondents is now larger (see Tables 2 and 3). As expected, a Cramér's $V$ of 0.115 suggests an even smaller effect size compared to the entire sample, which may be due to the partial control of group differences considering SU's reasonably homogeneous graduate profile.

\section{Mode effect in terms of Job Search Behaviour}

Table 4 shows job search behaviour by survey mode for the entire sample, again with highlighted response categories where both standardized residuals equalled \pm 3 or higher/lower. Recall that the question on job search behaviour offered the maximum number of response categories of all questions in the survey - 18 categories in total.

In this scenario, only two of the 18 response categories may have been subject to significant mode effects, namely graduates who 'responded to a job ad in the Government Gazette', and graduates who were 'headhunted or asked to apply for the job'. A statistically significant larger percentage of telephonic respondents had replied to an ad in the Government Gazette compared to web respondents ( $6 \%$ as opposed to $3 \%$ ). However, the fact that a significantly larger percentage of graduates from previously disadvantaged groups (combined) were telephonic respondents compared to 
Table 4.Graduates' primary method of finding employment by survey mode (all four universities).

\begin{tabular}{|c|c|c|c|c|}
\hline \multirow{2}{*}{$\begin{array}{l}\text { What was the primary method } \\
\text { of finding the job you had on } \\
\text { the } 1^{\text {st }} \text { of September 2012? }\end{array}$} & \multirow{2}{*}{ Statistics } & \multicolumn{3}{|c|}{ Survey mode } \\
\hline & & Web & Telephonic & Total \\
\hline \multirow{4}{*}{$\begin{array}{c}\text { A holiday job or internship gave } \\
\text { me access to this job }\end{array}$} & Count & 108 & 168 & 276 \\
\hline & Exp. Count & 141.6 & 134.4 & 276.0 \\
\hline & $\%$ & 5.7 & 9.3 & 7.5 \\
\hline & Std. residual & -2.8 & 2.9 & \\
\hline \multirow{4}{*}{ Through help of a lecturer } & Count & 93 & 53 & 146 \\
\hline & Exp. Count & 74.9 & 71.1 & 146.0 \\
\hline & $\%$ & 4.9 & 2.9 & 3.9 \\
\hline & Std. residual & 2.1 & -2.1 & \\
\hline \multirow{4}{*}{$\begin{array}{c}\text { Through my university's career } \\
\text { office }\end{array}$} & Count & 82 & 110 & 192 \\
\hline & Exp. Count & 98.5 & 93.5 & 192.0 \\
\hline & $\%$ & 4.3 & 6.1 & 5.2 \\
\hline & Std. residual & -1.7 & 1.7 & \\
\hline \multirow{4}{*}{$\begin{array}{l}\text { I initially offered to work for } \\
\text { free }\end{array}$} & Count & 16 & 9 & 25 \\
\hline & Exp. Count & 12.8 & 12.2 & 25.0 \\
\hline & $\%$ & .8 & .5 & .7 \\
\hline & Std. residual & .9 & -.9 & \\
\hline \multirow{4}{*}{$\begin{array}{l}\text { I had to work off a bursary I got } \\
\text { from my employer }\end{array}$} & Count & 105 & 84 & 189 \\
\hline & Exp. Count & 97.0 & 92.0 & 189.0 \\
\hline & $\%$ & 5.5 & 4.7 & 5.1 \\
\hline & Std. residual & .8 & -.8 & \\
\hline \multirow{4}{*}{$\begin{array}{l}\text { I simply sent in my CV or asked } \\
\text { for work }\end{array}$} & Count & 341 & 284 & 625 \\
\hline & Exp. Count & 320.7 & 304.3 & 625.0 \\
\hline & $\%$ & 18.0 & 15.8 & 16.9 \\
\hline & Std. residual & 1.1 & -1.2 & \\
\hline \multirow{4}{*}{$\begin{array}{c}\text { I responded to a job ad in the } \\
\text { printed media }\end{array}$} & Count & 216 & 251 & 467 \\
\hline & Exp. Count & 239.6 & 227.4 & 467.0 \\
\hline & $\%$ & 11.4 & 13.9 & 12.6 \\
\hline & Std. residual & -1.5 & 1.6 & \\
\hline \multirow{4}{*}{$\begin{array}{l}\text { I responded to a job ad on an } \\
\text { employment website }\end{array}$} & Count & 155 & 155 & 310 \\
\hline & Exp. Count & 159.1 & 150.9 & 310.0 \\
\hline & $\%$ & 8.2 & 8.6 & 8.4 \\
\hline & Std. residual & -.3 & .3 & \\
\hline \multirow{4}{*}{$\begin{array}{l}\text { I responded to a job ad on a } \\
\text { company website }\end{array}$} & Count & 123 & 107 & 230 \\
\hline & Exp. Count & 118.0 & 112.0 & 230.0 \\
\hline & $\%$ & 6.5 & 5.9 & 6.2 \\
\hline & Std. residual & .5 & -.5 & \\
\hline \multirow{4}{*}{$\begin{array}{l}\text { I responded to a job ad in the } \\
\text { Government Gazette }\end{array}$} & Count & 54 & 112 & 166 \\
\hline & Exp. Count & 85.2 & 80.8 & 166.0 \\
\hline & $\%$ & 2.8 & 6.2 & 4.5 \\
\hline & Std. residual & -3.4 & 3.5 & \\
\hline \multirow{4}{*}{$\begin{array}{c}\text { I placed ads or flyers } \\
\text { advertising my services on } \\
\text { notice boards or post-boxes }\end{array}$} & Count & 4 & 3 & 7 \\
\hline & Exp. Count & 3.6 & 3.4 & 7.0 \\
\hline & $\%$ & .2 & .2 & .2 \\
\hline & Std. residual & .2 & -.2 & \\
\hline \multirow{4}{*}{ I walked from door-to-door } & Count & 12 & 21 & 33 \\
\hline & Exp. Count & 16.9 & 16.1 & 33.0 \\
\hline & $\%$ & .6 & 1.2 & .9 \\
\hline & Std. residual & -1.2 & 1.2 & \\
\hline \multirow{4}{*}{$\begin{array}{l}\text { Through one of the Department } \\
\text { of Labour's employment centres }\end{array}$} & Count & 4 & 23 & 27 \\
\hline & Exp. Count & 13.9 & 13.1 & 27.0 \\
\hline & $\%$ & .2 & 1.3 & .7 \\
\hline & Std. residual & -2.6 & 2.7 & \\
\hline Through a recruitment agency & Count & 66 & 65 & 131 \\
\hline
\end{tabular}




\begin{tabular}{|c|c|c|c|c|}
\hline \multirow{5}{*}{$\begin{array}{l}\text { What was the primary method } \\
\text { of finding the job you had on } \\
\text { the } 1^{\text {st }} \text { of September } 2012 ? \\
\text { or labour broker }\end{array}$} & \multirow[b]{2}{*}{ Statistics } & \multicolumn{3}{|c|}{ Survey mode } \\
\hline & & Web & Telephonic & Total \\
\hline & Exp. Count & 67.2 & 63.8 & 131.0 \\
\hline & $\%$ & 3.5 & 3.6 & 3.5 \\
\hline & Std. residual & -.1 & .2 & \\
\hline \multirow{4}{*}{ Through family or friends } & Count & 205 & 226 & 431 \\
\hline & Exp. Count & 221.1 & 209.9 & 431.0 \\
\hline & $\%$ & 10.8 & 12.5 & 11.6 \\
\hline & Std. residual & -1.1 & 1.1 & \\
\hline \multirow{4}{*}{ Through a social network } & Count & 18 & 17 & 35 \\
\hline & Exp. Count & 18.0 & 17.0 & 35.0 \\
\hline & $\%$ & .9 & .9 & .9 \\
\hline & Std. residual & .0 & .0 & \\
\hline \multirow{4}{*}{$\begin{array}{l}\text { I was headhunted or asked to } \\
\text { apply for the job }\end{array}$} & Count & 169 & 43 & 212 \\
\hline & Exp. Count & 108.8 & 103.2 & 212.0 \\
\hline & $\%$ & 8.9 & 2.4 & 5.7 \\
\hline & Std. residual & 5.8 & -5.9 & \\
\hline \multirow{4}{*}{$\begin{array}{l}\text { I was promoted internally to this } \\
\text { position }\end{array}$} & Count & 128 & 71 & 199 \\
\hline & Exp. Count & 102.1 & 96.9 & 199.0 \\
\hline & $\%$ & 6.7 & 3.9 & 5.4 \\
\hline & Std. residual & 2.6 & -2.6 & \\
\hline \multirow{4}{*}{ Total } & Count & 1899 & 1802 & 3701 \\
\hline & Exp. Count & 1899 & 1802 & 3701 \\
\hline & $\%$ & 100.0 & 100.0 & 100.0 \\
\hline & Non-response & $60(3.1 \%)$ & $106(5.1 \%)$ & $166(4.3 \%)$ \\
\hline \multicolumn{5}{|c|}{$\begin{array}{l}\text { Notes: Question only applicable to those who were employed in the private or public sector, excluding } \\
\text { those self-employed in the private sector. } \\
\chi^{2}(17)=167.392 ; \mathrm{p}=0.000 ; \mathrm{n}=3701 ; \text { Cramér's } V=0.213\end{array}$} \\
\hline
\end{tabular}

white graduates, and given that most government jobs are reserved for previously disadvantaged groups, it again suggests that differences here between web and telephonic respondents may be due to group differences more so than mode effect. On the other hand, a significantly larger percentage of web respondents were headhunted compared to telephonic respondents (9\% as opposed to $2 \%$ ). Being headhunted depends on social capital in the form of having access to social and professional networks.

Research in fact suggests that whites in South Africa have stronger social and professional networks compared to previously disadvantaged groups (CHEC 2013), which again suggests that differences here between web and telephonic respondents may be due to group differences more so than mode effect. The role of social capital is however also hypothesised, although, on the other hand, if mode would have had a significant effect here, one may have expected a larger percentage of telephonic 
respondents to have been 'headhunted' due to social desirability bias. Yet, this outcome does not seem to be the case here.

In contrast to the first scenario in which employment status is presented for the entire sample, not only are there noticeably larger numbers of non-responses in this scenario, with web refusals increasing from 44 to 60 and telephonic refusals from 17 to 106 (totalling 166 in this scenario as opposed to 61 in the first), telephonic refusals have in fact more than doubled and have exceeded web refusals in this scenario (see Tables 2 and 4). Moreover, given that this scenario includes employed graduates only whereas the first includes all graduates, the increases in refusals are particularly pronounced as is evident in the proportional increases from $1.5 \%$ to $3.1 \%$ for web respondents and $0.6 \%$ to $5.1 \%$ for telephonic respondents (totalling $4.3 \%$ in this scenario compared to $1.1 \%$ in the first). The large number of response categories in this scenario is likely to have had a noticeable impact on refusals, especially telephonic refusals. Whereas the literature suggests that web respondents are more prone to refusals than telephonic respondents, the opposite seems to hold when a question includes a large number of response categories. However, the effect of possible interviewer misbehaviour may also contribute to non-responses.

A Cramér's $V$ of 0.213 suggests that survey mode had an overall medium to small effect on 'job search behaviour' as far as the entire sample is concerned. Although this is higher than the 0.146 statistic in the first scenario (see Table 2), overall effect size is likely to be smaller if one again ascribes some of the response variations between web and telephonic respondents to group differences rather than mode effect. Mode effect again did not appear to have significantly influenced the overall outcome of the question, although the noticeable increase in refusals, especially amongst telephonic 
respondents, stands out. Lastly, Table 5 shows job search behaviour by survey mode for

SU only.

Table 5. Graduates' primary method of finding employment by survey mode (SU only).

\begin{tabular}{|c|c|c|c|c|}
\hline \multirow{2}{*}{$\begin{array}{l}\text { What was the primary method } \\
\text { of finding the job you had on } \\
\text { the } 1^{\text {st }} \text { of September 2012? }\end{array}$} & \multirow{2}{*}{ Statistics } & \multicolumn{3}{|c|}{ Survey mode } \\
\hline & & Web & Telephonic & Total \\
\hline \multirow{4}{*}{$\begin{array}{c}\text { A holiday job or internship gave } \\
\text { me access to this job }\end{array}$} & Count & 19 & 28 & 47 \\
\hline & Exp. Count & 25.6 & 21.4 & 47.0 \\
\hline & $\%$ & 3.4 & 5.9 & 4.5 \\
\hline & Std. residual & -1.3 & 1.4 & \\
\hline \multirow{4}{*}{ Through help of a lecturer } & Count & 42 & 10 & 52 \\
\hline & Exp. Count & 28.4 & 23.7 & 52.0 \\
\hline & $\%$ & 7.4 & 2.1 & 5.0 \\
\hline & Std. residual & 2.6 & -2.8 & \\
\hline \multirow{4}{*}{$\begin{array}{c}\text { Through my university's career } \\
\text { office }\end{array}$} & Count & 14 & 35 & 49 \\
\hline & Exp. Count & 26.7 & 22.3 & 49.0 \\
\hline & $\%$ & 2.5 & 7.4 & 4.7 \\
\hline & Std. residual & -2.5 & 2.7 & \\
\hline \multirow{4}{*}{$\begin{array}{l}\text { I initially offered to work for } \\
\text { free }\end{array}$} & Count & 7 & 3 & 10 \\
\hline & Exp. Count & 5.5 & 4.5 & 10.0 \\
\hline & $\%$ & 1.2 & .6 & 1.0 \\
\hline & Std. residual & .7 & -.7 & \\
\hline \multirow{4}{*}{$\begin{array}{l}\text { I had to work off a bursary I got } \\
\text { from my employer }\end{array}$} & Count & 33 & 28 & 61 \\
\hline & Exp. Count & 33.3 & 27.7 & 61.0 \\
\hline & $\%$ & 5.8 & 5.9 & 5.9 \\
\hline & Std. residual & .0 & .0 & \\
\hline \multirow{4}{*}{$\begin{array}{l}\text { I simply sent in my CV or asked } \\
\text { for work }\end{array}$} & Count & 99 & 62 & 161 \\
\hline & Exp. Count & 87.8 & 73.2 & 161.0 \\
\hline & $\%$ & 17.5 & 13.1 & 15.5 \\
\hline & Std. residual & 1.2 & -1.3 & \\
\hline \multirow{4}{*}{$\begin{array}{c}\text { I responded to a job ad in the } \\
\text { printed media }\end{array}$} & Count & 73 & 89 & 162 \\
\hline & Exp. Count & 88.3 & 73.7 & 162.0 \\
\hline & $\%$ & 12.9 & 18.8 & 15.6 \\
\hline & Std. residual & -1.6 & 1.8 & \\
\hline \multirow{4}{*}{$\begin{array}{l}\text { I responded to a job ad on an } \\
\text { employment website }\end{array}$} & Count & 45 & 36 & 81 \\
\hline & Exp. Count & 44.2 & 36.8 & 81.0 \\
\hline & $\%$ & 7.9 & 7.6 & 7.8 \\
\hline & Std. residual & .1 & -.1 & \\
\hline \multirow{4}{*}{$\begin{array}{l}\text { I responded to a job ad on a } \\
\text { company website }\end{array}$} & Count & 24 & 17 & 41 \\
\hline & Exp. Count & 22.4 & 18.6 & 41.0 \\
\hline & $\%$ & 4.2 & 3.6 & 3.9 \\
\hline & Std. residual & .3 & -.4 & \\
\hline \multirow{4}{*}{$\begin{array}{l}\text { I responded to a job ad in the } \\
\text { Government Gazette }\end{array}$} & Count & 18 & 38 & 56 \\
\hline & Exp. Count & 30.5 & 25.5 & 56.0 \\
\hline & $\%$ & 3.2 & 8.0 & 5.4 \\
\hline & Std. residual & -2.3 & 2.5 & \\
\hline \multirow{4}{*}{$\begin{array}{l}\text { I placed ads or flyers } \\
\text { advertising my services on } \\
\text { notice boards or post-boxes }\end{array}$} & Count & 1 & 0 & 1 \\
\hline & Exp. Count & .5 & .5 & 1.0 \\
\hline & $\%$ & .2 & 0.0 & .1 \\
\hline & Std. residual & .6 & -.7 & \\
\hline \multirow{4}{*}{ I walked from door-to-door } & Count & 2 & 2 & 4 \\
\hline & Exp. Count & 2.2 & 1.8 & 4.0 \\
\hline & $\%$ & .4 & .4 & .4 \\
\hline & Std. residual & -.1 & .1 & \\
\hline
\end{tabular}




\begin{tabular}{|c|c|c|c|c|}
\hline \multirow{2}{*}{$\begin{array}{l}\text { What was the primary method } \\
\text { of finding the job you had on } \\
\text { the } 1^{\text {st }} \text { of September 2012? }\end{array}$} & \multirow[b]{2}{*}{ Statistics } & \multicolumn{3}{|c|}{ Survey mode } \\
\hline & & Web & Telephonic & Total \\
\hline \multirow{4}{*}{$\begin{array}{l}\text { Through one of the Department } \\
\text { of Labour's employment centres }\end{array}$} & Count & 2 & 5 & 7 \\
\hline & Exp. Count & 3.8 & 3.2 & 7.0 \\
\hline & $\%$ & .4 & 1.1 & .7 \\
\hline & Std. residual & -.9 & 1.0 & \\
\hline \multirow{4}{*}{$\begin{array}{c}\text { Through a recruitment agency } \\
\text { or labour broker }\end{array}$} & Count & 18 & 12 & 30 \\
\hline & Exp. Count & 16.4 & 13.6 & 30.0 \\
\hline & $\%$ & 3.2 & 2.5 & 2.9 \\
\hline & Std. residual & .4 & -.4 & \\
\hline \multirow{4}{*}{ Through family or friends } & Count & 66 & 70 & 136 \\
\hline & Exp. Count & 74.1 & 61.9 & 136.0 \\
\hline & $\%$ & 11.6 & 14.8 & 13.1 \\
\hline & Std. residual & -.9 & 1.0 & \\
\hline \multirow{4}{*}{ Through a social network } & Count & 4 & 4 & 8 \\
\hline & Exp. Count & 4.4 & 3.6 & 8.0 \\
\hline & $\%$ & .7 & .8 & .8 \\
\hline & Std. residual & -.2 & .2 & \\
\hline \multirow{4}{*}{$\begin{array}{c}\text { I was headhunted or asked to } \\
\text { apply for the job }\end{array}$} & Count & 56 & 11 & 67 \\
\hline & Exp. Count & 36.5 & 30.5 & 67.0 \\
\hline & $\%$ & 9.9 & 2.3 & 6.4 \\
\hline & Std. residual & 3.2 & -3.5 & \\
\hline \multirow{4}{*}{$\begin{array}{l}\text { I was promoted internally to this } \\
\text { position }\end{array}$} & Count & 44 & 23 & 67 \\
\hline & Exp. Count & 36.5 & 30.5 & 67.0 \\
\hline & $\%$ & 7.8 & 4.9 & 6.4 \\
\hline & Std. residual & 1.2 & -1.4 & \\
\hline \multirow{4}{*}{ Total } & Count & 567 & 473 & 1040 \\
\hline & Exp. Count & 567 & 473 & 1040 \\
\hline & $\%$ & 100.0 & 100.0 & 100.0 \\
\hline & Non-response & $21(3.6 \%)$ & $43(8.3 \%)$ & $64(5.8 \%)$ \\
\hline
\end{tabular}

In this scenario, only one of the 18 response categories may have been subject to significant mode effect, namely graduates who were 'headhunted or asked to apply for the job'. A significantly larger percentage of web respondents were headhunted compared to telephonic respondents (10\% as opposed to $2 \%)$, which again is more likely due to group differences rather than mode effect as discussed in the previous scenario. However, web refusals now increased from to $1.1 \%$ in the second scenario (where employment status is presented for SU only) to $3.6 \%$ in this scenario, while telephonic refusals now increased from $1.1 \%$ to $8.3 \%$, totalling $5.8 \%$ in this scenario compared to $1.1 \%$ in the second (see Tables 3 and 5). Moreover, a Cramér's $V$ of 0.285 
suggests that survey mode now had a near medium effect on 'job search behaviour' as far as the subsample of SU is concerned. This fourth and last scenario reiterates the point earlier that a noticeable increase in response categories is associated with noticeable mode effect, both in terms of overall effect size and non-responses.

\section{Conclusion}

The purpose of this article was to examine mode effect in a sequential mixed-mode graduate destination survey. The 2010 Western Cape graduate destination survey showed that a design in which web responses are augmented with telephonic responses will not necessarily change the overall outcome of a study. However, telephonic mode clearly impacts responses to categorical questions with numerous response categories more so than web mode.

Although Dillman et al. $(2009,1)$ argued that mixed-mode surveys is an effective way to improve response rates, and although the Western Cape survey showed that augmenting web with telephonic responses will not necessarily change the overall outcome of a study, some differences between web and telephonic responses were also noted that may well be a concern. Since it is impossible to determine the actual extent to which effect size was due to group differences rather than mode effect, suffice to conclude that web responses to alumni or graduate destination surveys can perhaps be augmented with telephonic responses if necessary. Yet, this conclusion should be seen in light of the following; As mentioned before, some studies do suggest that web is equally if not more viable and reliable than telephonic mode (e.g., see Braunsberger, Wybenga and Gates [2007], Kreuter, Presser and Tourangeau [2008, 864], and Stephenson and Crête [2010]). Some contextual and practical considerations also favour web, particularly for alumni or graduate destination surveys. For example, web surveys avoid the increasingly negative impact of telemarketing on people's willingness to 
answer anonymous calls or grant lengthy telephonic interviews. Web surveys are generally more time- and cost effective, while the availability of email addresses from university records may enable most alumni or graduates to be contacted via web. Also, web surveys alone are simply easier to design and administer given that one has to contend with the effects of a single mode only.

Still, mixing modes may well be necessary to increase coverage for alumni or graduate destination surveys, especially in developing countries like South Africa where socio-economic differences between graduates may influence access to different modes. Should web be combined or augmented with telephonic mode, then it is important to design and manage surveys to account for the effects of the two different modes on responses, particularly telephonic mode. For example, response categories to categorical questions should be kept to a minimum for the sake of telephonic interviews. Limiting response categories will help to lessen both interviewer- and respondent fatigue and enable respondents to better recall items, thereby reducing mode effect. Items susceptible to social desirability bias or acquiescence should then also be treated with caution. Telephonic interviewers should be trained properly and monitored for possible interviewer misbehaviour. Further research is necessary regarding graduate preferences for different modes when participating in alumni or destination surveys.

\section{Acknowledgements}

The Cape Higher Education Consortium (CHEC) entirely funded the 2010 Western Cape Graduate Destination survey on which this article is based. The following institutional researchers assisted with the compilation of the sample frame; Carmelita Benjamin (UWC), David Bleazard (CPUT), Jane Hendry (UCT), Neil Grobbelaar (SU) and Zandile Tennyson (UCT). The author would like to thank Dr Lizelle Fletcher from the Department of Statistics, University of Pretoria, for her inputs regarding effect sizes, as well as the three reviewers whose constructive comments served to improve the article. 


\section{References}

Agresti, A. 1990. Categorical data analysis. New York: John Wiley \& Sons.

Albaum, G., D. Klein, R. D. Rogers, and C. A. Roster. 2004. “A comparison of response characteristics from web and telephone surveys." International Journal of Market Research 46 (3): 359-367.

Alderman, L., S. Towers, and S. Bannah. 2012. "Student feedback systems in higher education: a focussed literature review and environmental scan." Quality in Higher Education 18 (3): 261-280.

Braunsberger, K., H. Wybenga, and R. Gates. 2007. "A comparison of reliability between telephone and web-based surveys." Journal of Business Research 60: 758-764.

Cape Higher Education Consortium. 2013. Pathways from university to work: A graduate destination survey of the 2010 cohort of graduates from the Western Cape Universities. Wynberg: Cape Higher Education Consortium.

Cohen, J. 1992. “A power primer.” Psychological Bulletin 112 (1): 155-159.

De Leeuw, E. D. 2005. "To mix or not to mix data collection modes in surveys." Journal of Official Statistics 21 (2): 233-255.

Dillman, D. A., and L. M. Christian. 2005. "Survey mode as a source of instability in responses across surveys." Field Methods 17 (1): 30-52.

Dillman, D.A., G. Phelps, R. Tortora, K. Swift, J. Kohrell, J. Berck, and B. L. Messer. 2009. "Response rate and measurement differences in mixed-mode surveys using mail, telephone, interactive voice response (IVR) and the internet." Social Science Research 38: 1-18.

Du Toit, J., A. Kraak, J. Favish, and L. Fletcher. 2014. "From study to work: Methodological challenges of a graduate destination survey in the Western Cape, South Africa.” Assessment \& Evaluation in Higher Education 39 (7): 853864.

Greene, J., H. Speizer, and W. Wiitala. 2008. "Telephone and web: Mixed-mode challenge." Health Services Research 43 (1): 230-248.

Kreuter, F., S. Presser, and R. Tourangeau. 2008. "Social desirability bias in CATI, IVR, and web surveys: The effects of mode and question sensitivity." Public Opinion Quarterly 72 (5): 847-865. 
Maguire, K. B. 2009. "Does mode matter? A comparison of telephone, mail, and inperson treatments in contingent valuation surveys." Journal of Environmental Management 90: 3528-3533.

Reinard, J. C. 2006. Communication research statistics. Thousand Oaks: Sage Publications.

Sakshaug, J. W., T. Yan, and R. Tourangeau. 2010. "Nonresponse error, measurement error, and mode of data collection: Tradeoffs in a multi-mode survey of sensitive and non-sensitive items." Public Opinion Quarterly 74 (5): 907-933.

Stephenson, L. B., and J. Crête. 2010. "Studying political behavior: A comparison of internet and telephone surveys." International Journal of Public Opinion Research 23 (1): 24-55.

Taylor, H. 2000. "Does internet research work? Comparing online survey results with telephone survey." International Journal of Market Research 42 (1): 51-63.

Van der Berg, S., and H. Van Broekhuizen. 2012. Graduate unemployment in South Africa: A much exaggerated problem. Stellenbosch Economic Working Papers 22/12. A working paper of the Department of Economics and the Bureau for Economic Research at the University of Stellenbosch.

Vannieuwenhuyze, J., G. Loosveldt, and G. Molenberghs. 2010. “A method for evaluating mode effects in mixed-mode surveys." Public Opinion Quarterly 74 (5): 1027-1045. 